\title{
O Senior Executive Service: especial referência ao perfil do Top Public Service em Portugal
}

Pedro Nunes

\section{Introdução}

Alguns dos países da OCDE (2002) enfrentam, hoje, problemas relacionados ao emprego público e à sua competitividade (recrutamento, retenção de pessoal, falta crítica de habilidades e competências, etc.). Em nível de recrutamento (OCDE, 2002), os países que já identificaram o problema são o Canadá, a Dinamarca e a Finlândia; a falta crítica de habilidades e de competências foi já identificada por: Itália, Coreia, Noruega, Polónia, Portugal ${ }^{1}$, Espanha, Áustria e Alemanha.

O desenho e a implementação de estratégias de recursos humanos nas organizações públicas desenrolam-se em ambiente altamente politizado (LACOVIELLO, 1996) e o processo de decisão está sujeito a influências que tomam proporções maiores pelas características particulares que apresentam e pelo conflito essencial que decorre das relações entre políticos e burocratas. Nos modelos existentes, afigura-se uma série de relações entre a política e a administração: por um lado aqueles dirigentes que desempenham apenas funções 
políticas ou, pelo menos, estão comprometidos com a agenda política; por outro, aqueles que, sem estarem comprometidos com essa agenda política, seguem objectivos e estratégias traçadas por aqueles; e, por outro ainda, aqueles que desempenham função estritamente fora da influência do factor político.'

Quase todos os sistemas de serviço público dos países da OCDE contemplam a existência de estrutura de pessoal político de confiança do Governo (Oszlack, 2001), em que se incluem, por exemplo, gabinetes ministeriais, assessores de gabinetes, presidentes e directores de empresas públicas, directores e subdirectores-gerais, etc. Essas designações abarcam o pessoal de livre nomeação e/ou de escolha política, que não possui estabilidade no emprego e normalmente se desvincula do mandato ou da comissão com a saída do ministro que o tutela. Nesse contexto, a literatura faz referência aos seguintes cargos: 1) cargos políticos de eleição; 2) cargos políticos de livre designação; e 3) altos cargos públicos de livre designação política. Concluímos que, dos grupos assinalados (cargos políticos e altos cargos públicos), faz-se alguma confusão conceptual com outras especificidades. Dito de outro modo, os diplomas legais não são claros na separação entre: 1) cargos políticos de eleição (embora aqui seja fácil encontrar o itinerário e/ou significado); 2) cargos políticos de livre designação, de confiança política; e 3) altos cargos públicos de livre designação, de confiança política. O presente trabalho intenta fazer uma caracterização, ainda que muito sumária, dos altos cargos públicos de livre designação, de confiança política, que compõem, com algumas excepções tratadas mais adiante, o Senior Executive Service (SES). Para uma grande parte de países, o SES inclui o
Top Public Service (TPS), que, no caso português, abarca os cargos de direcção superior ( $1^{\circ}$ grau: Director-Geral, Presidente, Secretário-Geral e InspectorGeral; $2^{\circ}$ grau: Subdirector-Geral, VicePresidente, Adjuntos de Secretário-Geral, Vogal de Direcção e Subinspector-geral), e o Top Management Service (TPM), que, no caso português, abarca os cargos de direcção intermédia $\left(1^{\circ}\right.$ grau: Director de Serviços; $2^{\circ}$ grau: Chefe de Divisão). Trataremos, com especial referência, como se indicia, dos cargos de direcção superior.

\section{Relação entre políticos e burocratas}

A clássica dicotomia wilsoniana e, em particular, a relação entre ministros e burocratas não é um assunto novo na área da administração pública (BRANs et al., 2002), sendo, em todo o caso, mais uma expressão do que uma realidade (PopIK, 1998). Como refere Jacobsen (2001), a distribuição do poder entre as esferas é um clássico na ciência política, desde Weber e Wilson. Por um lado, os políticos tomam decisões e, por outro, os burocratas são quem as executa e, muitas vezes, influencia fortemente as decisões dos próprios políticos. É, de resto, a posição de Shergold (1997) acrescentando que os burocratas são uma parte da máquina do Estado. Aberbach (1981) refere que as tendências históricas fizeram do século XX o século do político profissional e do profissional burocrata do Estado. Observa-se, assim, que a esfera politica e a esfera administrativa assinaladas por Smith (1984) e Greenwood e Wilson (1989), citados em Parrado-Díez (1996), são ambíguas: por um lado, a identificação dos cargos relacionados com um processo de eleição, que são, portanto, cargos políticos de livre escolha; por outro 
lado, os cargos assinalados como altos cargos públicos (não políticos), mas de livre designação política. Petermann (2001) faz uma curta referência ao trabalho de Aberbach, em que este autor descreve as tipologias de relações, distinguindo quatro tipos correspondentes a quatro modelos, a saber: 1) relação de tipo I: funcionário como executante neutro (tipo de funcionário conforme o desenho de Weber ou de Wilson, que não participa na elaboração das políticas públicas); 2) relação de tipo II: funcionário como conselheiro (nesse caso, o burocrata público tem uma latitude que lhe permite participar no processo de decisão); 3) relação de tipo III: funcionário como mandatário; e 4) relação de tipo IV: funcionário "híbrido", antítese do funcionário de Weber.

A teoria que viria a desencadear a problemática sobre a relação entre políticos e burocratas foi a clássica, da separação de poderes (MACHADO, 1999). É uma evidência que a formulação e a implementação das políticas públicas dependem, em grande medida, do equilíbrio no relacionamento entre políticos e burocratas (PoLLiTT, 1990), não sendo possível afastar esta relação, que, como refere Eymeri (2001), tem sido, no quadro dos Estados ocidentais, a partir da década de 1980, objecto de inúmero estudos e trabalhos. Tem-se constatado, pois, que há uma inseparável complementaridade entre políticos e burocratas no mundo moderno (АвERBACH, 1981). Weber já insistia que a relação entre políticos e burocratas é marcada pela tensão entre os objectivos de ambos e que a resposta a essa situação deve ser a da constituição de um confronto dinâmico e capaz de assegurar o controlo mútuo e que a direcção do Estado será sempre política (Loureiro; Abrucio; Rosa, 1998). O aparecimento dos dirigentes supõe (Longo, 1997) uma ruptura com essa grandeza profundamente interiorizada. Peters (1999) sugere, para controlar o poder da burocracia, um conjunto de actuações, tais como: 1) manipulação das estruturas, criando gabinetes que complementem as estruturas existentes e tradicionalmente dominadas pelos funcionários; 2) controlo do recrutamento nos postos mais elevados; 3 ) tentativa de mudar as atitudes e a cultura das pessoas que ocupam os postos mais

“Os burocratas
vêm gradualmente
ganbando espaço
aos polúticos na
definição da missão
e dos objectivos e da
orientação política;
por sua vez, os
políticos têm cada
vez mais
necessidade de se
envolverem nos
problemas da
administração e da
gestão.

elevados e de maior responsabilidade; e 4) alteração do nível em que se tomam as decisões. Contributos importantes têm surgido, tal como a posição de Peters (1987) e Sevic (2001), considerados pontos de vista de enorme actualidade. $O$ primeiro propõe os seguintes modelos: 1) o modelo paroquial (village life); o modelo funcional (functional village life); o modelo adversário (adversarial); o modelo de Estado 
administrativo (administrative State); e o modelo formal-legal (formal-legal, weberian State). O functional village life e o village life são os mais comuns em termos de modelos usados na Europa continental. Não é verdade que assim seja em todos os casos, dependendo, sempre, das especificidades de cada país, dos sistemas legais, da cultura política, das características da democracia, etc. (SEvic, 2001). De todo modo, as dimensões apresentadas por Peters (ibid.) carácter das interacções, os actores que conquistam o controlo do processo decisório, o estilo de resolução dos conflitos, os procedimentos; e o tipo de impacto dos diferentes padrões de interacção sobre as políticas adoptadas pelo Governo - mais não são do que distinções analíticas sobre os padrões de interacção de políticos e burocratas no processo de policy-making.

Apesar do que se alega, é hoje consensual que a simples divisão do trabalho dos burocratas e dos políticos deve coexistir em duas esferas de actuação distintas, posição que vem sendo, aliás, diluída ao longo dos tempos, até por comprovação de estudos empíricos. Com modelos de relações fortemente politizadas, há o caso da Itália, Bélgica e França (neste caso até bastante integrado); com modelos separados e razoavelmente politizados, há o caso da Finlândia, da Austrália, da Alemanha, do Japão e da Holanda; com modelos de separação das esferas e, portanto, muito pouco ou nada politizados, há o exemplo da Nova Zelândia e do Reino Unido.

Os burocratas vêm gradualmente ganhando espaço aos políticos na definição da missão e dos objectivos e da orientação política; por sua vez, os políticos têm cada vez mais necessidade de se envolverem nos problemas da administração e da gestão. Mais longe, julgámos, vai James Svara (1999), que constrói um modelo a que chama de "Dichotomy-Duality-Model" (cf. Figura 1), um arquétipo inspirado no clássico modelo de decisão e no clássico modelo de Weber (HANSEN et al., 2002), comportando quatro dimensões, a saber: missão, política, administração e gestão. Segundo o autor, os políticos baseiam mais

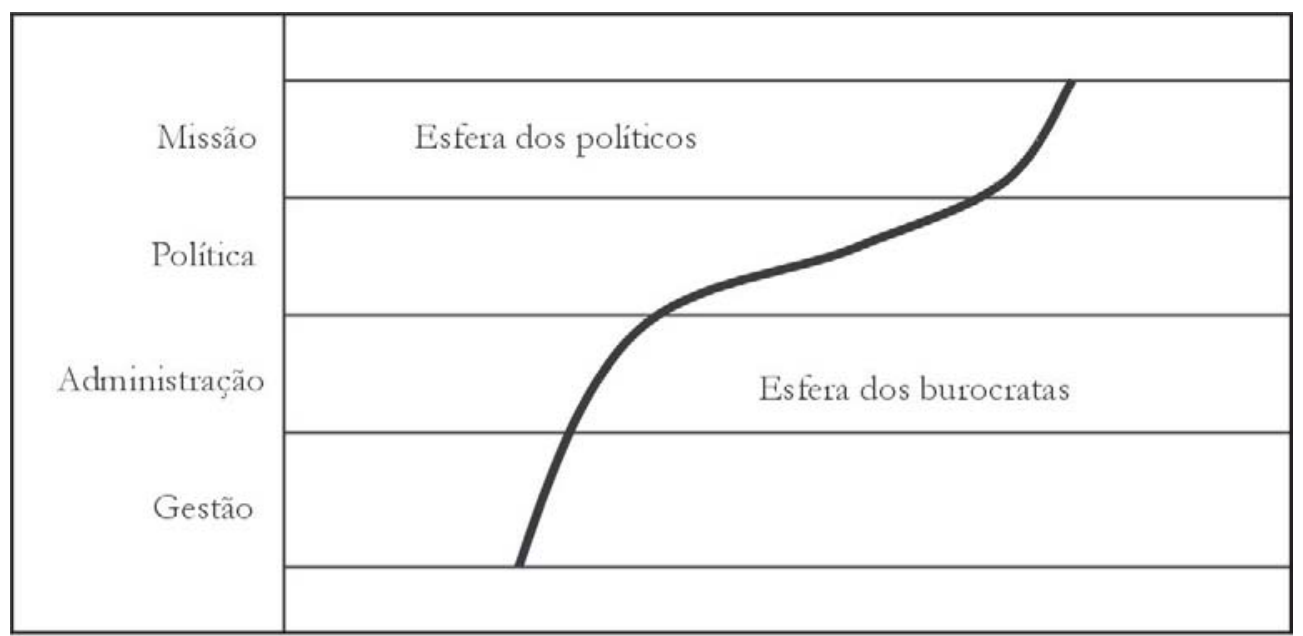

Fonte: Hansen et al., 2002

Figura 1: O modelo "dicotômico-dualidade" de relações entre políticos e burocratas 
a sua actuação em comportamento caracterizado por lógica indutiva de acção e os burocratas, por lógica dedutiva. Os primeiros assentam a sua actuação na política do eleitorado e os segundos, na lógica das leis, dos procedimentos e regulamentos, dos objectivos e valores. Apesar do que se expõe, hoje parece abandonada a ideia de separação radical entre política e administração (JACOBSEN, 2001); políticos e burocratas são vistos como duas esferas que se encaixam.

\section{Conceitos e designações adap- tados para os dirigentes públicos}

Tomando o exemplo de países como o Reino Unido, os EUA, a França e o Canadá, pode observar-se que as designações para a função directiva não são únicas e não têm as mesmas especificidades de ingresso, acesso, tipo de contrato, etc. Assim, e com referência aos lugares mais elevados ou às elites da função direcção, podem encontrar-se designações como: senior executive service, executive group, seniorpublic service, senior civil service, dirigenza publica, grupo de pessoal dirigente, gestores governamentais, grands corps, hoher Dienst, etc. É importante, por isso, relembrar que, em alguns casos, não se faz a distinção das escolhas da dos lugares de carreira. Assim, e para o grupo dos Senior Managers (sistema conhecido por Senior Public Service (SPS), Senior Executive Systems ou Public Management Systems (PMS) ou, como se vê em Curado (1999), Corporate Managers Career, Political Executive System, Public Elite Corps Career e Agency Specialists Career), do que foi dito, e com especificidades de alguns países, é de se salientar que, por exemplo, para o caso da Austrália, do Canadá, da Alemanha, da França e da Suécia, a posição de head of ministers e a de chefes executivos das agências não fazem parte do SES (contrariamente ao Reino Unido), como o caso do EUA em que as top positions não fazem parte do SES.

Todos os países, ou pelo menos quase todos os sistemas políticos, têm uma etiqueta ou designação para as posições que dirigem as organizações administrativas (Parrado-Díez, 2000). Trata-se do political appointee nos EUA, o funcionário político (politische Beamte) na Alemanha e os cargos de designación politica na Espanha e, ainda, os vulgarmente conhecidos em Portugal como cargos de escolha política.

O tamanho do SPS, SES e PMS será determinado, normalmente, pelo tamanho do funcionalismo público, e a extensão das funções administrativas superiores incluirá o TPS e o TMS. O tamanho líquido do TPS deve ser o bastante, de forma a permitir a flexibilidade no alocamento dos indivíduos, mas pequeno bastante para permitir o desenvolvimento do espírito de corpo. Por exemplo, nos EUA, o SES federal têm aproximadamente $8 \mathrm{mil}$ membros $(0,2 \%$ do total serviço civil federal); a dirigenza italiana representa $2 \%$ do serviço civil total; na Suécia, um programa especial de desenvolvimento foi experimentado para 200 a 300 directores gerais das agências, que representam menos de 1/1.000 do serviço total do civil service. Contudo, não encontramos na literatura argumentos suficientes em favor de uma tese para a identificação de cargos dirigentes. Para o caso português, o número de dirigentes representava, em 1999, 1,2\% do total do funcionalismo público. No cômputo do total dos dirigentes (8.427), está incluída toda a administração pública (mesmo a subnacional), num total de 713.472. Se excluirmos a administração autárquica, num total de 116.066, e os 1.605 dirigentes afectos a este tipo de 
administração, a percentagem dos dirigentes fica em 1,14\%. Em vários estudos da OCDE, esses grupos ocupam entre $1 \%$ e $2 \%$ do total da administração pública (apenas a administração central), mas, como há países com critérios diferentes para a integração ou não nos próprios níveis, fica difícil estabelecer qualquer relação comparativa.

No caso português, as sucessivas leis e outros diplomas regulamentares em matéria de pessoal dirigente são muito vagas na conceptualização de tal designação, expressando-se apenas: "considera-se pessoal dirigente o pessoal que exerce actividade de direcção, gestão, coordenação e controlo nos serviços e organismos públicos". Os vários estudos sobre o pessoal dirigente enfatizam diversificadas noções para o pessoal dirigente, ou altos directivos da administração pública, como se representa na Figura 2, seguinte.
Desse modo, clarifica-se que, quando se faz referência ao pessoal dirigente e/ou directivos, estamos a falar do pessoal que se enquadra no conceito de Senior Managers como parte do Senior Public Service ${ }^{2}$, que inclui os lugares de escolha política (Top Public Service) e os lugares providos por concurso (Top Management Service).

De resto, a designação Senior Public Service enfatiza a ideia, para o grupo do Senior Managers, de recursos: (OCDE, 2001): 1) que, em muitos casos, assumem perímetros demasiado grandes de serviço com cultura compartilhada; 2) detentores de elevada experiência; 3) comprometidos com o governo e conhecedores da agenda política; e 4) com elevadas competências de direcção e gestão. É consentâneo, em vários estudos da OCDE, que as funções do Senior Public Service são, designadamente: 1) o estabelecimento de relações e ligações entre ministros (gabinetes, agências, etc.)

\begin{tabular}{|c|c|c|}
\hline 1 & 2 & 3 \\
\hline 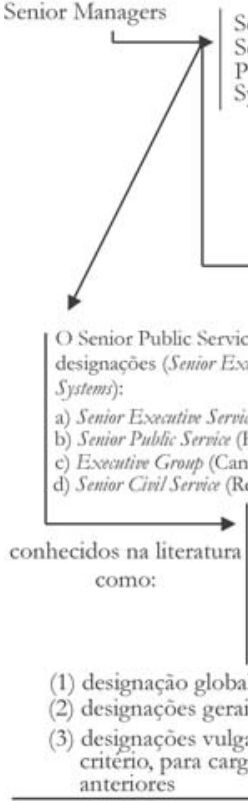 & 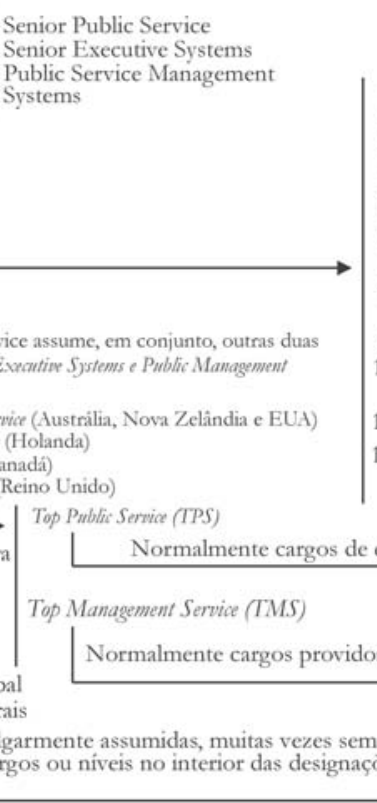 & 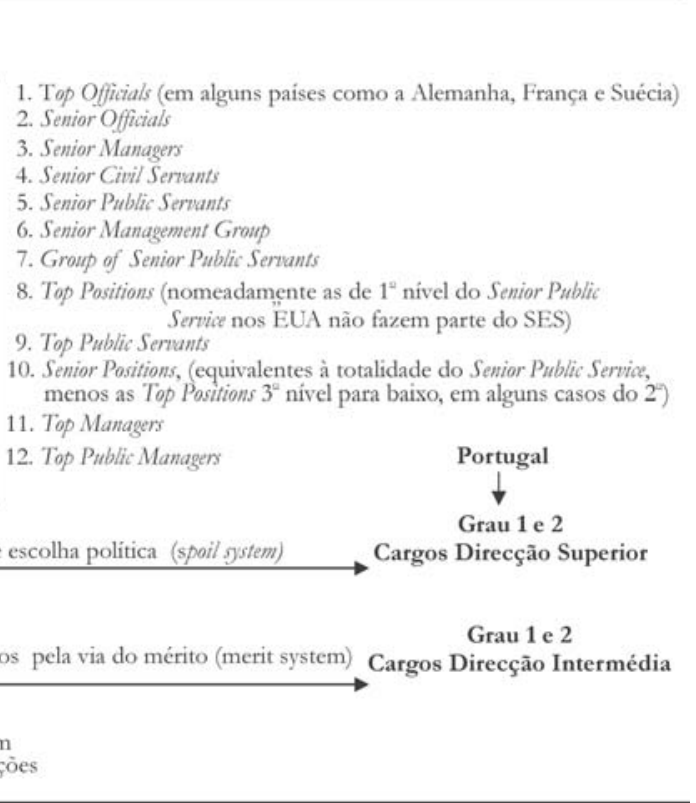 \\
\hline
\end{tabular}

Figura 2: Esquema-tipo de designações mais comuns para os Senior Managers 
onde nenhuma estrutura existe (actividades interdepartamentais ou interministeriais); e 2) o desenvolvimento do funcionalismo público.

Quanto à influência desses altos funcionários e/ou altos directivos da administração pública, ou altos dirigentes, vulgarmente conhecidos na língua inglesa como Top Public Servants (geralmente o $1^{\circ}$ nível é de escolha política, mas, em alguns casos, também o é o $2^{\circ}$ nível) e Top Management Servants (geralmente do $3^{\circ}$ nível para baixo, designados pelo sistema de mérito), cumpre fazer algumas referências, como: OCDE (1995, 1996, 1997a; 1998, 2001); Korsmit e Valders (1997); Sotiropoulos e Bourikos (1999); Parrado-Díez (2000); Bekke e Meer (2001); Harb (2001); Braun (2001); Laforte e Godin (2001); Waintrop et al. (2003); Bourgault et al. (2003); Silguy (2003), tendo em conta alguns países da OCDE, num contexto de reforma da administração pública e nos casos relacionados com o grupo de pessoal dirigente, como, por exemplo, no Reino Unido, nos EUA, na França, etc.

\section{Características do Senior Executive Service em Portugal e em países de referência}

Para o Reino Unido, a criação do Senior Civil Service (SCS), em 1996, teve a ver, essencialmente, com: 1) estímulo ao recrutamento de líderes do sector privado; 2) estímulo à cultura de resultados na gestão das agências; e 3) profissionalismo e sentido de visão e coesão entre os diferentes ministérios. Em termos de perímetro, o SCS reagrupa perto de 3.200 funcionários (dados de 2000). As designações típicas são: permanent secretary, director, deputy director e agency chief executives. Nos EUA, paralelamente ao sistema de nomeações políticas, o SES foi criado, em 1978, com os objectivos de: 1) promover um sistema global de gestão de quadros dirigentes que permitisse a despolitização da administração central; 2) melhorar o sistema de rotação e de mobilidade dos quadros dirigentes; 3) reconhecer as responsabilidades individuais e as remunerações, a decisão de promoções; e 4) responsabilizar-se pelos resultados individuais e organizacionais. A ênfase e o privilégio no contexto das reformas do SES foram dados às competências de liderança e não às competências técnicas. Em termos de perímetro, o SES compreende 6.600 dirigentes (dados de 2002) nos postos mais elevados da administração. As designações típicas do SES são: deputy assistant secretary, office or division director, branch chief.

$\mathrm{Na}$ França, os altos dirigentes da função pública são normalmente conhecidos como elite que cultiva a meritocracia. Essa elite é constituída por dois grupos: 1) os grandes corpos administrativos; e 2) os grandes corpos técnicos do Estado. Observando a elite burocrática da França e comparando-as com as do Reino Unido, verifica-se que elas são mais instruídas, pois são formadas pela ENA, desde 1945 (BREZIs, 2002). As características, assim como as grandes mudanças do poder e no poder das elites burocráticas francesas, aconteceram, essencialmente, a partir da Segunda Guerra Mundial. De Gaulle considerava que os tradicionais burocratas falharam nos seus deveres, principalmente nos anos 30 e no "Vichy Regime", tendo havido a necessidade de mudar o recrutamento e a formação dos servidores do Estado. Por essas razões, foi criada a Ecole Nationale d'Administration (ENA). Na Áustria, o SES foi criado pela reforma do sector público, em 1984, que tinha como prioridade reduzir a permanência dos 
servidores públicos nos cargos, diversificar as fontes de assessoramento político aos ministros e incrementar a capacidade gerencial (PoLLiTT et al., 2000). Na Bélgica, foi lançado, em 2000, um programa denominado "Copérnico", com quatro objectivos: 1) uma nova estrutura organizacional; 2) uma nova cultura managerial; 3) uma nova visão dos recursos humanos; e 4) novos métodos de trabalho. Para a Nova Zelândia, singularizou-se a gestão do grupo de altos dirigentes, como os secretários-gerais dos ministérios, recrutados pelas sua capacidade de liderar, gerir estruturas autónomas e assumir compromissos de resultados, e, ainda, os secretários-gerais adjuntos e outros responsáveis superiores. O programa do SES visou, essencialmente, a reforçar o perfil de liderança dos dirigentes públicos. Em termos de perímetro, esse programa é constituído por dois níveis: os postos de secretáriosgerais dos ministérios, que são claramente identificados pelas funções e não fazem parte do SES, e os postos do SES (Top Managers), que são determinados pelo State Service Commission e são, por lei, em número de 500, nos seguintes níveis: $1^{\circ}$ nível: state services commissioner, $2^{\circ}$ nível: chief executive, secretary, director-general; e $3^{\circ}$ nível: deputy director-general, assistant director-general, manager e general manager. Como se pode aferir, apenas a título de exemplo, na base da criação desses corpos ou dessas elites de altos dirigentes ou directivos públicos, está uma mesma filosofia, traduzida na busca de competências estritamente relacionadas com a visão estratégica, o desenvolvimento de programas de avaliação da performance, a gestão e a planificação de recursos humanos, físicos e económicos, etc.

Em referência a outras especificidades, mantêm-se, ainda, algumas diferenças, que vão, de resto, ao encontro das próprias iniciativas das reforma lançadas em cada país. Sabemos, hoje, que, embora a Austrália, o Canadá, a Holanda e os EUA não possuam contratos específicos para a função, a evolução aponta para esse tipo de mecanismo do sistema de emprego e não para o tradicional sistema de carreira. Muitos países não possuem um sistema de administração, ou estatuto próprio, para o Senior Public Service; contudo, alguns países possuem características especiais que distinguem ou privilegiam, de alguma forma, esse tipo de trabalhador (OCDE, 1998). Todos os países possuem disposições para prazos previamente fixados, com excepção da Austrália, Dinamarca, Irlanda e Turquia (embora na Austrália a saída possa acontecer, existindo mesmo a figura da indemnização, como é o caso de Portugal), pela falta de produtividade. Na Dinamarca, a renovação é automática. Para a Irlanda, embora não existam disposições especiais para o termo do emprego, os membros do Senior Civil Servant podem ser demitidos.

Os contratos de performance, ainda pouco formalizados, são uma prática em crescimento, veja-se o caso dos chefes executivos das agências (heads of agencies). De salientar-se, neste particular, o caso da Dinamarca e Noruega, que têm contratos especiais de performance. Em resumo, pode dizer-se que é comum aos países que têm sido referenciados as seguintes características (OCDE, 1998): 1) ênfase nas competências e habilidades de gestão, menos que nas competências de especialidade; 2) mudanças no recrutamento e nas formas de nomeação e acesso aos cargos no Senior Public Service, eliminando progressivamente a antiguidade (seniority) como factor de acesso ou critério; 3 ) maior atenção ao desenvolvimento de carreiras; e 4) incremento da diversidade no Senior Public Service, 
no sentido de recrutar mais mulheres, pessoas de outras línguas ou de etnias minoritárias, embora se saiba que nenhuma administração opera com sistema completamente puro. São conhecidas as típicas excepções, a saber: 1) nomeações e/ou escolhas políticas; e 2) mecanismos afirmativos (quando, por exemplo, se adoptam sistemas de protecção a determinados grupos que se julgam desprotegidos e/ou estão em concorrência desleal. Em Portugal, a obrigatoriedade de, na abertura de concursos públicos, nomeadamente nos respectivos editais, fazer-se referência ao princípio da igualdade entre homens e mulheres no acesso à função pública, é disso exemplo). Assim, é por demais claro, por tudo o que de menos favorável possa dizer a opinião pública, que as nomeações políticas são parte importante de qualquer estrutura governamental (CHANDA, 2001) e que, mesmo estas, não estão obviamente arredadas do mérito, como muitas vezes se julga. Assim, convém frisar que o facto de a selecção e o recrutamento não serem politizados não significa que não esteja afastada a influência política, embora se reconheçam algumas vantagens ao sistema de mérito, apresentadas pelo mesmo autor: 1) oferece a melhor garantia de competência dos funcionários; 2) a neutralidade facilita a colaboração; 3) a politização evade-se a quase todo o tipo de controlo; 4) uma administração competente e apolítica é condição de integridade para os cidadãos; e 5) uma administração neutra é condição essencial para assegurar a continuidade do serviço público em caso de alternância política.

Por comparação com outros os países, pode ver-se que a Bélgica, Dinamarca, Noruega e Suíça são o grupo de países que mais se distancia do nosso regime jurídico, não havendo qualquer tipo de declaração de inexistência de incompatibilidades e/ou de conflitos de interesse no exercício do cargo; próximo do nosso regime estão os EUA, o Reino Unido, a Turquia, a Austrália, a Áustria e a Alemanha. No caso da Islândia, há apenas uma declaração oral e, no da Holanda, ela é deixada a critério do titular do cargo. De resto, pode dizer-se que a confidencialidade da declaração de interesses é comum, normalmente, aos países que possuem

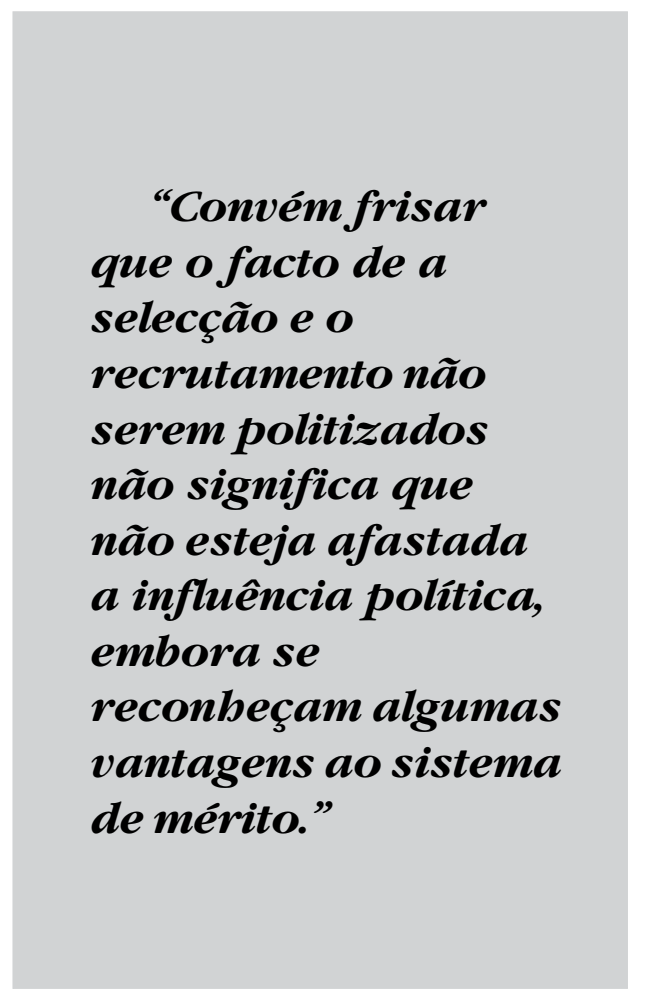

regime jurídico de incompatibilidades muito próximo do nosso (Irlanda, México e Turquia), mas é proibida a sua divulgação em países como os EUA e a Finlândia. É de se destacar que se presta especial atenção ao nível político, incluindo o Parlamento, na Itália, no Japão, na Nova Zelândia e em Portugal (OCDE, 2000), e membros de gabinetes, na Itália, no Japão, na Nova Zelândia, em Portugal e na Espanha. Na 
generalidade, todos os países com maior ou menor rigidez têm requerimentos de declaração mais rigorosos para políticos e executivos do que os restantes funcionários, não implicando isso que estes não tenham qualquer tipo de restrição. Nas situações de pós-exercício do cargo de dirigente, existem, para a maioria dos países, algumas restrições formais, em alguns casos até bastante restritivas, como no caso dos EUA. Na França, por exemplo, nenhum indivíduo que tenha exercido um cargo no Senior Public Service e, em face disso, tenha participado na supervisão ou controlo de empresas ou tenha relações governamentais ligadas à empresa, poderá, num período de cinco anos, exercer qualquer actividade nessa empresa ou sector. O mesmo se passa no Japão, mas em um período que poderá oscilar entre dois e cinco anos. Já, na Nova Zelândia, não há qualquer restrição formal. O México, estando numa situação de proibição, só o faz, contudo, pelo período de um ano após o exercício de cargo no Senior Public Service. Em Portugal, o regime jurídico começou por contemplar o período de um ano, estendendo-se, hoje, a três anos de separação entre o exercício de alto cargo público ou político e o exercício de função e eventual cargo em empresas privadas cujas actividades foram por ele directamente tuteladas.

Formação, recrutamento e selecção dos dirigentes em Portugal e em países de referência

É manifesta, em nível de doutrina formal, a preocupação de fazer coincidir o atributo da confiança política com o da capacidade e do saber-fazer no domínio da gestão pública. Isso explica a tendência para aplicar processos de formação mais rigorosos, recorrendo-se para o efeito, em alguns países, a peritos independentes, a empresas privadas especializadas em selecção de recursos humanos. No caso de Portugal, o Instituto Nacional de Administração (INA) tem assumido papel fundamental na formação dos quadros superiores e intermédios.

O recrutamento, em Portugal, para os cargos de director-geral e subdirector-geral ou equiparados $\left(1^{\circ}\right.$ e $2^{\circ}$ nível, segundo classificação da OCDE (1997), e $1^{\circ}$ e $2^{\circ}$ grau, cargos de direcção superior, segundo a Lei $n^{\circ} 2$, de 15/1/2004), é feito por livre designação e/ou escolha do poder político, recaindo essa escolha em indivíduos licenciados, vinculados ou não à administração pública, que possuam competência técnica, aptidão, experiência profissional e formação adequadas ao exercício das respectivas funções.

Por comparação com outros países, podem tirar-se duas conclusões: a primeira tem a ver com um grupo de países que se aproxima do sistema de carreira (careersystem approach): Bélgica, França e Japão são talvez os melhores exemplos de que ascender às posições seniores é quase um processo de promoção interna (sem processo formal de selecção, como, por exemplo, entrevista), embora não se possa dizer que seja um processo automático de promoção (OCDE, 1998). Aqui, pensamos dever incluir Portugal, já que os candidatos são oriundos, nomeadamente, da administração. A Alemanha e a Irlanda são também exemplos de um sistema aproximado de carreira em que os lugares são preenchidos pelos níveis inferiores das posições seniores, sem reservas de recrutamento para o exterior da administração pública, embora haja um processo formal de selecção, mas sem uso formal de critérios nesse mesmo processo de selecção em nível de competências; só mesmo a 
Austrália, o Canadá, a Finlândia, a Nova Zelândia, o Reino Unido e os EUA o fazem (uso de critérios de selecção em nível de competências). De referir que, em Portugal, para o grau 1 e 2 dos cargos de direcção intermédia, o processo de selecção sofreu avanços significativos, tendo-se acrescentado ao tempo de serviço e à licenciatura, como requisitos de recrutamento, um outro requisito extremamente importante, um curso de formação específica (Curso de Alta Direcção em Administração Pública), que inclui várias áreas de competências (Gestão de Pessoas e Liderança; Gestão de Recursos Orçamentais, Materiais e Tecnológicos; Tecnologia e Administração Electrónica; Qualidade, Inovação e Modernização; Internacionalização e Assuntos Comunitários, entre outros), bastante próximas das dos países reformadores e com experiências inovadoras nessa área.

Em contraste aos sistemas quase de carreira do primeiro grupo de países, estão os países nórdicos, que têm um sistema de position-based systems, como a Holanda, a Áustria, a Nova Zelândia, o Reino Unido e os EUA. Possuem um sistema aberto de acesso e nenhum sistema de qualificação formal para que tais cargos sejam ocupados (como o tempo de serviço). Contudo, como aliás já referimos, mesmo nos países que operam num sistema de recrutamento aberto, a maioria das designações e/ou nomeações que ocorre é de indivíduos que vêm do sector público, e não do sector privado. O envolvimento de uma agência central é cada vez menos usado como procedimento para o recrutamento para o Senior Public Service e, em particular, para as posições senior. Quanto às condições formais de acesso, só um número muito restrito de países, como o Japão, Portugal e a Turquia, explicitamente, exigem o tempo de serviço como requisito essencial, embora existam excepções, mesmo em Portugal, como já referimos. A Bélgica e a França exprimem, contudo, algumas especificidades, tal como reservar o acesso a cargos, como por exemplo, aos membros dos corpos do Civil Administrators. Em nível dos critérios de selecção, apenas seis países (Austrália, Canadá, Finlândia, Nova Zelândia, Reino Unido e EUA) estabeleceram o uso formal de critérios de selecção em relação às competências.

Quanto à mobilidade no Senior Public Service, cumpre referir que as políticas para os sistemas de gerência pública não são comuns (em termos de existência formal) na maioria dos países da OCDE, existindo, contudo, cada vez mais incentivos ao mecanismo de criação de novos instrumentos. As políticas de mobilidade têm como objectivos essenciais: 1) promover o interesse colectivo do governo e de suas funções; 2) incentivar as organizações que têm a seu cargo o desempenho do serviço público a beneficiarem-se do intercâmbio de novas ideias, procedimentos e tecnologias; 3) evitar que as organizações tenham pessoal subaproveitado, que, em outras posições, não o seria; e 4) promover o intercâmbio do sector público com o sector privado.

Existe um grupo de países bastante empenhado na introdução de mecanismos de avaliação do desempenho dos dirigentes, que estabelecem as metas anuais de desempenho, o perfil do cargo para cumprimento das metas, os objectivos e as acções diante de desempenhos insatisfatórios. Em Portugal, as avaliações estruturais eram feitas muito raramente, contrariamente ao que ocorria na Bélgica, na Nova Zelândia, no Reino Unido e nos EUA. E as metas de avaliação do desempenho ficavam por conta de uma espécie 
de acordo entre o dirigente e o ministro responsável (OCDE, 1988). Mas, hoje, em Portugal, dois documentos foram publicados com o sentido de reformar e prestigiar o grupo de pessoal dirigente: $\mathrm{o}$ novo Sistema de Avaliação do Desempenho na Administração Pública (SIADAP), em que se inclui a avaliação do desempenho dos próprios dirigentes, e a Lei $\mathrm{n}^{\circ}$ 2, de 15/1/2004 (Estatuto do Pessoal Dirigente).

O processo de selecção desses quadros superiores deverá orientar-se pela busca de pessoas capacitadas e com características pessoais que favoreçam o posicionamento como agentes de mudança (GIORDAN, 2002). É importante, assim, promover a adaptação do recrutamento ao mercado de trabalho, como faz a Alemanha, a agilização das formas de selecção (Espanha), a ampliação do concurso aberto para o acesso aos postos superiores, inclusivamente, o recrutamento de dirigentes por meio de métodos semelhantes aos do sector privado (Irlanda e Inglaterra), o desenvolvimento da contractualização (Dinamarca) e a agilização das regras sobre a carreira (Luxemburgo e Alemanha) (SARAVIA, 1997).

São por demais conhecidos os ataques à solução "carreira", dos quais se destacam: o corporativismo às expensas do interesse público; a tendência à expansão infinita; a tendência à burocratização; a propensão para maximizar e modelar os orçamento; e a ineficiência e inércia estruturais. O estudo de Schnapp (1999), tendo por base um inquérito por questionário (em diversos países), para o funcionalismo público em geral, em que se abordaram várias questões (como, por exemplo, o reconhecimento da experiência no sector privado e sua valorização no sector público, o recrutamento centralizado ou não, diplomas e/ou habilitações especiais para carreiras específicas, remunerações estatutárias, períodos probatórios, etc.), resultou, para o conjunto dos países em referência, na tendência que se tem assinalado relativamente ao sistema de emprego. De facto, um conjunto de países, como a Holanda, a Suécia, a Finlândia, a Dinamarca, o Reino Unido e a Itália, reduziu ou, pelo menos, manteve baixos índices de características que indiciam um processo de recrutamento que promova um sistema de carreira.

O país com um sistema de recrutamento mais aberto é a Nova Zelândia (3.7, conforme Tabela 1), que tem, como já vimos, características e fortes tradições de país reformador da administração pública e forte implementador no New Public Management (NPM). Poder ver-se, do mesmo modo, que a Noruega, a Bélgica, Portugal, a Áustria e a Suíça, com 4.0 cada, possuem também recrutamento para o SES comparativamente aberto. Ressalve-se, contudo, que, no caso de Portugal, se, por um lado, é verdade que em termos formais (requisitos legais e especiais de acesso) pode ser considerado um sistema aberto de recrutamento, por outro, na prática, o recurso a candidatos vindos do exterior à administração pública é quase inexistente. A Holanda, o Canadá, a Austrália e o Reino Unido possuem (dados de 1990) sistemas de recrutamento fechado para o Senior Executive Service, sendo certo que a Holanda e o Reino Unido se opõem a uma tendência contrária para a generalidade do funcionalismo público. Se, por um lado, Portugal se encontra no grupo desses mesmos países (pelo menos em termos de requisitos especiais formais) com razoável abertura no processo de recrutamento para as posiçōes sénior na administração pública, por outro, é, também, juntamente com a França e a Alemanha, o país com maior potencial, formal, de politização no processo de selecção e recrutamento do SES. 
São, como se pode ver na Tabela 1, a Dinamarca, o Reino Unido, a Áustria, a Bélgica e os EUA os países que têm, assim, o mais baixo grau, formal, de politização dos níveis/graus mais elevados da administração pública. No Reino Unido, por exemplo, quando muda o gabinete ou algum ministro, o número de cargos à disposição de quem chega é mínimo. Menos de duas vezes no caso do primeiroministro e menos de uma no caso de um ministro (WAiNTrop et al., 2003). A tradição de uma burocracia neutra e fortemente profissionalizada está profundamente enraizada na cultura política britânica e, apenas mais recentemente, vem sofrendo pressões politizadoras, nomeadamente com Thatcher e Blair.

$\mathrm{Na}$ França, o escopo para a substituição dos quadros é maior, porém a opção favorecida pelos governantes e ministros é o recurso aos oriundos das grandes escolas, com a diferença de que os escolhidos são os alinhados politicamente com os titulares do Executivo.

Existe, contudo, uma série de problemas que se coloca ao recurso a outsiders, por exemplo, o horizonte limitado

Tabela 1: Grau de abertura do recrutamento para o SES, politização formal e praticabilidade de actividades políticas daquele grupo (primeira metade dos anos 90)

\begin{tabular}{lccc}
\hline Países & $\mathbf{1}$ & $\mathbf{2}$ & $\mathbf{3}$ \\
\hline Holanda & 5.9 & 1.0 & 4.0 \\
\hline Canadá & 5.9 & 0.5 & 2.0 \\
\hline Austrália & 5.8 & 1.5 & 2.0 \\
\hline Reino Unido & 5.6 & 2.0 & 0.0 \\
\hline Suécia & 5.0 & 1.0 & 4.0 \\
\hline Dinamarca & 5.0 & 3.0 & 1.0 \\
\hline Finlândia & 5.0 & 1.0 & 4.0 \\
\hline França & 5.0 & 0.0 & 4.0 \\
\hline Alemanha & 5.0 & 0.0 & 4.0 \\
\hline Irlanda & 5.0 & 1.0 & 0.0 \\
\hline EUA & 4.9 & 2.0 & 1.0 \\
\hline Noruega & 4.0 & - & 3.0 \\
\hline Bélgica & 4.0 & 2.0 & 4.0 \\
\hline Portugal & 4.0 & $\mathbf{0 . 0}$ & $\mathbf{3 . 0}$ \\
\hline Áustria & 4.0 & 2.0 & 4.0 \\
\hline Suíça & 4.0 & - & 3.0 \\
\hline Nova Zelândia & 3.7 & 1.0 & 3.0 \\
\hline Islândia & - & - & 4.0 \\
\hline Japão & - & - & 1.0 \\
\hline Font: Schan & & & \\
\hline
\end{tabular}

Fonte: Schnapp, 1999, adaptado

1) Recrutamento do SES (0-6, em que 6 traduz um sistema de recrutamento fechado)

2) Politização formal do SES (0-3, em que 0 traduz um elevado grau de politização formal)

3) Actividades políticas do SES, (1-4, em que 4 traduz não haver limites para actividades políticas) 
(normalmente o serviço ou trabalho é "adjudicado" pela via do contrato, fora do regime estatutário de carreira), a politização excessiva e o oportunismo.

A tarefa do recurso ao recrutamento de outsiders torna-se mais complexa na questão da competitividade dos salários (mais elevados nos quadros superiores do sector empresarial privado) e na exposição à sociedade (muitas vezes de desgaste e conotada com a crescente oposição da sociedade civil que relaciona essas posições com as relações de clientelismo). Se, por um lado, a contratualização, a flexibilidade do emprego é um corolário da NGP, oferecendo atractivos como a nitidez de papéis e responsabilidades, a objectivação e a contratualização de resultados, o alinhamento de incentivos organizacionais e individuais, por outro lado, são conhecidas, no sector público, as limitações ao uso de contratos como, por exemplo, todo um rol de normativos jurídicos e constitucionais, que impedem, de alguma forma, a curto prazo, a implementação desse mecanismo, que pode ser usado na generalidade da administração pública e, em particular, nas posições de topo no funcionalismo público, nomeadamente no sistema de contratação e/ou nomeações políticas, que podem e devem ser contratualizadas e, dessa forma, também ser contratualizados os resultados.

França, Portugal e Alemanha (SCHNAPP, 1999) são países que possuem

Tabela 2: Número de ministérios, tamanho do SES e rácio $\mathrm{SES} /$ ministério

\begin{tabular}{l|c|c|c|c}
\hline Países & Ano & Ministérios & Tamanho do SES & Rácio SES/ministério \\
\hline Nova Zelândia & 1985 & 20 & 123 & 6.2 \\
\hline Nova Zelândia & 1994 & 20 & 154 & 7.7 \\
\hline Suécia & 1991 & 21 & 396 & 18.9 \\
\hline Irlanda & 1985 & 17 & 449 & 26.4 \\
\hline Islândia & 1994 & 15 & 448 & 31.3 \\
\hline Japão & 1985 & 22 & 689 & 33.2 \\
\hline Japão & 1994 & 21 & 697 & 33.8 \\
\hline Holanda & 1991 & 14 & 473 & 35.1 \\
\hline Bélgica & 1991 & 18 & 631 & 38.6 \\
\hline Finlândia & 1985 & 17 & 656 & 38.5 \\
\hline Finlândia & 1991 & 17 & 655 & 42.7 \\
\hline Dinamarca & 1991 & 19 & 736 & 56.1 \\
\hline Noruega & 1991 & 19 & 811 & 98.6 \\
\hline França & 1991 & 20 & 1121 & 105.7 \\
\hline Áustria & 1991 & 17 & 1676 & 114.9 \\
\hline Alemanha & 1993 & 25 & 2643 & 169.1 \\
\hline Suíça & 1994 & 7 & 804 & 168.6 \\
\hline Reino Unido & 1985 & 21 & 3551 & 524.5 \\
\hline Reino Unido & 1994 & 23 & 3878 & 530.9 \\
\hline EUA & 1985 & 13 & 6818 & - \\
\hline EUA & 1993 & 14 & 7432 & - \\
\hline Portugal & 1994 & 17 & & \\
\hline
\end{tabular}

Fonte: Schnapp, 1999, adaptado. 
elevado controlo sobre o Senior Executive Service, até pelo índice ou grau de politização formal desses cargos $(0.0$ nos três países, cf. Tabela 1$)$, possuindo, desse modo, um extenso e alargado poder de influência sobre a burocracia. Por outro lado, na Dinamarca, no Reino Unido e na Áustria e, com algumas limitações, nos EUA, esse controlo é muito mais limitado, distanciando-se de um maior ou possível controlo sobre a burocracia. Os trabalhos de Downs (1965), Tulock (196?), Niskanen (1971) e Dunleavy (1991), citados em Gaetani (2002), demonstram que altos burocratas podem actuar de forma nociva ao interesse público, na medida em que perseguem o seu próprio interesse, cobertos pela protecção dos seus próprios cargos e pelo poder que detêm.

Os rácios (SES/n $\mathrm{n}^{\circ}$ de gabinetes e/ou ministérios, conforme Tabela 2) por gabinete ministerial são exemplos da enorme variedade e/ou do tamanho do Senior Executive Service; por um lado, um grupo de países, como a Nova Zelândia, a Suécia, a Irlanda, o Japão, a Holanda, a Bélgica, a Finlândia e a Dinamarca, com rácios que oscilam entre 6.2 e 38.7; por outro, países com rácios bastante mais elevados, como a Austrália, a Alemanha, a Suíça, o Reino Unido e os Estados Unidos, com uma variação entre 98.6 e 530.9, respectivamente, significando que, só em um número muito reduzido de países, o respectivo ministro pode manter contactos muito próximos com o Senior Executive Service. Além do mais, a posição da burocracia sai mais ou menos fortalecida no caso da Bélgica, da França e do Reino Unido, moderadamente na Áustria, na Irlanda, na Holanda, na Dinamarca e na Nova Zelândia e enfraquecida na Finlândia, na Alemanha, na Austrália, na Suécia e nos EUA.

Para Portugal (cf. Tabela 3), em referência ao perímetro do SES, pode mesmo dizer-se que tem vindo a aumentar a ritmos elevados nos últimos anos, aumento este muito mais significativo no XIII Governo Constitucional, o que é comum, também, a um generalizado aumento do universo de todo o pessoal dirigente.

De acordo com Curado (1999), o Senior Executive Service, para além das características apontadas, deverá ser um grupo profissional em que predomine a

Tabela 3: Número de ministérios, tamanho do SES e rácio SES/ministério, Portugal

\begin{tabular}{l|c|c|c|c|c}
\hline $\begin{array}{l}\text { Governo } \\
\text { constitucional }\end{array}$ & Ano & Ministérios & $\begin{array}{l}\text { Tamanho } \\
\text { do SES }\end{array}$ & $\begin{array}{l}\text { Rácio SES/ } \\
\text { ministério }\end{array}$ & $\begin{array}{l}\text { Rácio SES (DG, SDG } \\
\text { e equivalentes/ministério* }\end{array}$ \\
\hline IX & 1983 & 15 & 440 & 29,3 & - \\
\hline X & 1986 & 12 & 574 & 47,8 & - \\
\hline XI & 1988 & 14 & 652 & 46,6 & - \\
\hline XI & 1991 & 16 & 740 & 46,3 & - \\
\hline XII & 1996 & 15 & 807 & 53,8 & 485,3 \\
\hline XIII & 1999 & 16 & 1122 & 70,1 & 450,1 \\
\hline
\end{tabular}

Fonte: Construção nossa com as seguintes fontes: leis orgânicas dos vários governos constitucionais e base de dados da administração pública com referência ao número de dirigentes.

* Foram considerados todos os dirigentes (excluindo a ALA), sendo que na ALA, de 1996 para 1999, o número de dirigentes cresceu quase $80 \%$, passando de 629 para 1.224 dirigentes. 
Tabela 4: Comparação, por país/ano de 1991, do tamanho do SES e rácio SES/ministério

\begin{tabular}{l|c|c|c|c}
\hline Países & Ano & Ministérios & Tamanho do SES & Rácio SES/ministério \\
\hline Suécia & 1991 & 21 & 396 & 18.9 \\
\hline Holanda & 1991 & 14 & 473 & 33.8 \\
\hline Bélgica & 1991 & 18 & 631 & 35.1 \\
\hline Finlândia & 1991 & 17 & 655 & 38.5 \\
\hline Dinamarca & 1991 & 19 & 736 & 38.7 \\
\hline Noruega & 1991 & 19 & 811 & 42.7 \\
\hline Portugal & 1991 & 16 & 740 & 56.3 \\
\hline França & 1991 & 20 & 1121 & 98.6 \\
\hline Áustria & 1991 & 17 & 1676 & \\
\hline
\end{tabular}

Fonte: Schnapp, 1999. Adaptação e construção com tabelas do autor e dados nossos.

liderança e visão, com forte compromisso com o serviço público, e, ainda, que esteja habilitado para saber lidar com os trabalhadores no sentido de motivá-los, construir parcerias e comunicar com seus clientes. A localização dos cargos híbridos no topo da burocracia é um espaço intersectorial, considerado o cume nas relações entre políticos e burocratas. Três características devem ser reforçadas (Parrado-Díez, 1996): 1) os membros ou ocupantes de cargos híbridos deverão ser também responsáveis pela tomada de decisão, execução e/ou avaliação de políticas públicas de cobertura de âmbito nacional; 2) o recrutamento temporário para um cargo híbrido é decidido de acordo com critérios não meritocráticos; e 3) o acesso aos cargos híbridos é aberto também a pessoas externas ao sector público. Aqui, concordamos com Chanda (2001) quando refere que as nomeações políticas dão forma a uma parte importante da maioria das estruturas do governo e, por si só, variam conforme a estrutura desse mesmo governo; embora a vasta maioria dos postos seja preenchida por funcionários públicos de carreira dentro da burocracia, algumas das posições chaves em cada departamento podem ser preenchidas por pessoas externas à administração pública.
Breves proposições de estudo sobre os dirigentes de livre designação do poder político, as elites das direcções-gerais em Portugal, em $2003^{3}$

- Uma pequena parte dos ministérios (Economia, Obras Públicas, Justiça e Finanças) absorve mais de 50\% dos cargos dirigentes não equiparáveis na administração central do Estado;

- o Ministério da Finanças é o departamento que absorve mais nomeações políticas de dirigentes não equiparáveis na administração central (25,6\% dos cargos) do Estado;

- o Ministério da Cultura e o Ministério da Educação são os departamentos com maior número de nomeação de mulheres para cargos dirigentes (excluindo equiparados) na administração central do Estado;

- os Ministérios da Defesa, dos Negócios Estrangeiros e da Administração Interna são os departamentos com menor taxa de ocupação de cargos dirigentes por mulheres;

- a faixa etária predominante está compreendida entre 50 e 54 anos. Para a Austrália, em 2001, a faixa etária com maior número de dirigentes era de 50-54 anos; na Grécia, a maioria dos directores-gerais são homens $(75 \%)$ com idade compreendida 
entre 50-65 anos de idade; no Canadá, 40-49 anos (com 44,4\%); na Espanha, o grupo do SES é relativamente jovem, 78\% no caso dos directores-gerais, $77 \%$ no nível 30 e $61 \%$ no grupo A têm menos de 54 anos; na Itália, 71\% dos directores-gerais têm mais de 56 anos; na França, 78\% dos dirigentes situam-se na faixa etária entre 41 e 61 anos;

- a média etária dos directores e subdirectores-gerais é de 44.59, sendo bastante inferior à média nacional para o total do grupo de dirigentes em Portugal, com referência a 1996, que foi de 48.2 (IGBDRHAP, 1999) e superior, 43.1, para 1999 (IGBDRHAP, 2001). Essa média não sofreu, portanto, grandes variações de 1999 para 2003. Conclui-se que o grupo de pessoal dirigente, em especial o inquirido, não sofre, em termos de funcionalidade, qualquer problema de envelhecimento, uma vez que 48,1\% destes têm idades até inferiores a 44 anos, idade em que a relação conhecimento/rendimento está no auge (IGBDRHAP, 1999);

- a faixa etária com maior índice de envelhecimento, por cargo, encontrase nos directores-gerais homens, com $13,2 \%$ com idades compreendidas entre 50 e 54 anos; no mesmo cargo, 16,7\% das mulheres situam-se na faixa etária de 40-44 anos;

- a idade média dos homens dirigentes é superior à das mulheres, 45.7 e 42.2, respectivamente; para os EUA (ABRAMSON, 1999), a idade média no SES (em 1999) era de 53 anos;

- a maior taxa de concentração de homens dirigentes (sobre o total) situa-se na faixa etária dos 50-54 anos;

- as mulheres ocupam fundamentalmente lugares subalternos (grau 2, direcção superior) no topo da hierarquia da administração pública;
- globalmente as mulheres dirigentes são menos idosas que os homens;

- no global, os lugares de directoresgerais e subdirectores-gerais são preferencialmente providos por homens $(68,8 \%$ por homens e $31,2 \%$ por mulheres). Essa percentagem assume valores mais significativos na Grécia, com 75\%, e na Espanha, com 85\%, nos cargos mais elevados;

- a percentagem de homens nomeados para cargos de subdirector-geral é bastante menor por comparação com o cargo de director-geral, isto é, a preferência por mulheres é maior nos cargos de subdirectorgeral $(47 \%)$ do que nos de director-geral (4,6\%). No caso da Espanha, para os cargos de subdirector-geral, o fenómeno é idêntico, com 40\% de mulheres nesses cargos contra 15\% no nível 1. Fenómeno idêntico acontece na Itália com as mulheres a ocupando apenas 5\% dos cargos de director-geral e $20 \%$ dos de directores (a nossa correspondência a subdirectorgeral). No Reino Unido, a maioria dos directores-gerais são homens ( $60 \%$ no nível 1, 63\% no nível 2 e 45\% no nível 3);

- para as mulheres, a mais baixa taxa de ocupação de cargos dirigentes é no cargo de inspector-geral;

- a percentagem de cargos ocupados por mulheres em cargos dirigentes está muito próxima da média obtida (para 1996) nos órgãos de soberania e administração central $(35,8 \%)$, na administração regional $(37,3 \%)$ e na administração local (39,0\%) (IBDRHAP, 1999);

- a percentagem de mulheres ocupantes de cargos dirigentes, em particular nos cargos de direcção superior, tem vindo a aumentar. O ritmo de crescimento de 1996 para 1999 foi de 36\%, mas com substancial abrandamento de 1999 para 2003, com aumento de apenas 4\%. Em nível internacional a percentagem de mulheres nos cargos 
dirigentes (com referência a 2000) está a aumentar; sabe-se que, por exemplo nos EUA é de 25,2\%, no Reino Unido 22\%, na Alemanha $12 \%$ e na Austrália 26,15\%;

- do total dos inquiridos, a grande maioria $(98,8 \%)$ é detentora de grau universitário, pelo menos de licenciatura. Desse total, 67,9\% são licenciados, 18,5\% possuem pós-graduação, 9,9\% possuem mestrado e 1,2\% possui doutoramento;

- quanto à área de formação académica, uma parte significativa tem formação de base (licenciatura) em Direito (23,5\%) e em Engenharia (13,6\%), enquanto as áreas de Economia, Gestão e Finanças absorvem $18,5 \%$ do total $(7,4 \%, 9,9 \%$ e $1,2 \%$, respectivamente). $\mathrm{Na}$ Alemanha, por exemplo, o Direito $(29,4 \%)$ aparece, logo depois das Ciências Sociais, como um dos graus mais característicos do Senior Executive Service, seguido pelas Ciências Tecnológicas (18,7\%) e Economia (12\%). Na Itália, área jurídica ocupa lugar de destaque em termos de recrutamento e selecção para o SES (28\%), destacando-se também Portugal nas áreas de Engenharia com a maior taxa de ocupação. $\mathrm{Na}$ Espanha, não sendo, contudo, a maior taxa de ocupação (juristas) com 11,4\%, essa taxa é, contudo, das mais elevadas, sendo que, de 1982 para 1996, teve um ritmo de aumento que ultrapassou os 50\%. Page (1999) refere, contudo, que a percentagem, para Espanha, de membros do SES com formação universitária em Direito é de 45\%, seguida de Economia com $20 \%$ e outros diplomas técnicos com 20\%; a proporção dos que têm formação em Humanidades é relativamente baixa $(7 \%)$, assim como em Sociologia Política (5\%);

- nas áreas de formação para além da licenciatura, a preferência é: Direito 10,7\%, Gestão 10,7\%, Engenharia 7,1\% e Economia $7,1 \%$, com destaque para a Sociologia com 21,4\%;
- o número médio de anos, em termos de antiguidade, quer nos cargos dirigentes exercidos, quer na função pública, é de 4,2 anos para o $1^{\circ}$ caso e 16,4 anos para o $2^{\circ}$ caso;

- excluído o tempo de serviço prestado nos cargos de dirigente, $23,5 \%$ dos dirigentes possuem entre 21 e 25 anos de serviço na função pública, apesar dr a média global ser de 16.4 anos, aliás muito diferente nos EUA (para 1999), onde o tempo médio na função pública é de 25 anos;

- 11,1\% dos inquiridos já exerceram cargos de director-geral; 3,7\%, cargos de secretário-geral; 8,6\%, cargos de subdirectorgeral; $21 \%$, de director de serviços; 22,2\%, de chefe de divisão; e 13,6\%, de cargos equiparados a dirigentes;

- para Portugal, o tempo médio de permanência no SES é de 4,2 anos (direcção superior). Para os EUA, é de 8 anos;

- 93,8\% consideram muito importante e importante o contacto com políticas do governo central;

- mais de 50\% considera importante uma filiação partidária como factor de acesso ao cargo;

- 57,9\% possuem inscrição em ordens e associações profissionais;

- em média, os dirigentes supervisionam directamente 19.1 trabalhadores;

- em média, os dirigentes supervisionam indirectamente 71,9 trabalhadores;

- os dirigentes trabalham semanalmente, em média, mais horas no cargo actual do que no cargo de origem;

- apenas 26,9\% conhecem e fazem cumprir a Carta Ética e Deontológica do Serviço Público, 69,2\% ajuízam que conhecem razoavelmente o documento e 3,8\% nunca ouviram falar na carta;

- $17,3 \%$ estão a planear manter-se por um longo período de tempo no cargo actual; 
- num cenário de reforma ou aposentação, a grande maioria só pretende fazêlo num horizonte temporal de mais de 10 anos $(70,4 \%)$;

- 82,6\% não considerm a hipótese de trabalhar num cargo fora da função pública;

- $83,7 \%$ não querem mesmo mudar para o sector privado;

- por cargo, os dirigentes com mais expectativas em alcançar cargos mais elevados de eleição ou nomeação são os directores-gerais;

- por sexo, os dirigentes com mais expectativas em alcançar cargos mais elevados de eleição ou nomeação são os homens;

- globalmente, os dirigentes estão de acordo com a avaliação da sua peformance;

- globalmente, os homens estão mais receptivos à avaliação da sua performance;

- globalmente, a avaliação da performance deverá incidir simultaneamente na conduta e nos resultados;

- uma avaliação realizada unicamente em função dos resultados é defendida, essencialmente, pelas mulheres;

- o feedback da avaliação da performance dos dirigentes, da parte do membro do governo competente ou do superior hierárquico imediato, é feito com pouca regularidade;

- as maiores lacunas, em termos de familiaridade e frequência de programas de formação oferecidos por universidades e escolas superiores, são em nível da contabilidade pública, das finanças públicas e do desenvolvimento organizacional;

- os dirigentes têm acentuada preocupação pelo aperfeiçoamento em áreas mais técnicas de gestão do que propriamente em áreas de recursos humanos e de desenvolvimento organizacional;

- num futuro próximo (cinco anos), as competências principais a serem desenvolvidas pelos dirigentes são: criatividade e inovação; trabalho em equipa; liderança das pessoas; antecipação e iniciativa; capacidade intelectual e orientação para resultados;

- ao contrário do trabalho desenvolvido pelos seus congéneres noutros países, em Portugal os dirigentes têm funções maioritariamente técnicas e de especialidade do que de racionalidade organizacional; em

“Num futuro próximo (cinco anos), as competências principais a serem desenvolvidas pelos dirigentes são: criatividade e inovação; trabalbo em equipa; liderança das pessoas; antecipação e iniciativa; capacidade intelectual e orientação para resultados."

média $76 \%$ e $36,9 \%$, respectivamente, para a primeira e a segunda situação;

- as maiores dificuldades para o cumprimento da função directiva são: resistência à mudança, falta de recursos financeiros, estruturas burocráticas rígidas e problemas de motivação de equipas de trabalho;

- as tarefas relacionadas com o planeamento estratégico são realizadas sem carácter de continuidade; 
- as tarefas relacionadas com a liderança são realizadas com alguma regularidade;

- as tarefas relacionadas com a gestão de recursos humanos são realizadas com alguma regularidade;

- as tarefas relacionadas com a gestão de recursos (económicos e financeiros) são realizadas com continuidade (sempre);

- as tarefas relacionadas com a satisfação do cidadão não têm regularidade (quase nunca);

- a avaliação do impacto do serviço público na sociedade em geral é, das actividades dos dirigentes, a que é executada com menor regularidade;

- os dirigentes consideram, em média, possuir $70 \%$ a $80 \%$ das competências exigidas para a função;

- do trabalho ou função dos dirigentes, $80 \%$ a $100 \%$ é de racionalidade técnica (média de 76\%);

- do trabalho ou função dos dirigentes, menos de $50 \%$ é de racionalidade organizacional (média de 36,9\%);

- formalmente, o conjunto de competências atribuídas aos dirigentes em Portugal difere substancialmente do das competências atribuídas ao Senior Executive Service para a generalidade dos países da OCDE, sendo que, em Portugal, se privilegia o componente de racionalidade técnica para aquelas competências;

- os homens são mais peremptórios na afirmação e convicção de que possuem competências na área em que trabalham $(68,8 \%)$ do que as mulheres $(31,2 \%)$, como, aliás, o são na percepção que têm sobre se possuem suficiente e adequada autoridade e flexibilidade para gerir eficientemente (53,3\% para os homens e $46,7 \%$ para as mulheres);

- por cargos, os inquiridos providos nos lugares de director-geral são os mais convencidos (45,7\%) que possuem competência na área em que trabalham, contra
$32,5 \%$ de subdirectores-gerais e restantes cargos $(21,8 \%)$;

- por cargos, com referência à autoridade e flexibilidade para gerir eficientemente, a expressão recai, por ordem de importância, em: director-geral, 46,2\%; subdirector-geral, 30,8\%; e restantes cargos, $23 \%$;

- elevado receio perante possível redução de efectivos e flexibilização do emprego público;

- algum "incómodo" ou discordância com a integração de princípios e valores da gestão empresarial, ou de concorrência, ou ainda de sistemas de gestão não hierarquizado (gestão empresarial), fazendo com que os dirigentes não apelem à gestão por contratos e à fragmentação da organização e/ou actividades;

- a grande maioria considera que a imagem que a sociedade tem de si não é a melhor, isto é, ajuíza sem equívocos que a imagem dos dirigentes públicos em geral é péssima $21,8 \%$, razoável $52,6 \%$ e apenas 25,6\% consideram ser boa;

- $86,8 \%$ dos dirigentes consideram que o recrutamento deveria estar descentralizado por todos os níveis da administração pública, com perfeita autonomia dos órgãos directamente envolvidos ou interessados no recrutamento;

- 70,1\% concordam com o facto de o recrutamento para os cargos de DG e SDG ou equiparados ser feito por escolha do poder político. 29,9\% dos inquiridos estão em desacordo com essa opinião, considerando que deveriam estar sujeitos a concurso, tal como acontece com os dirigentes de direcção intermédia (bolsa de recrutamento);

- no global, os dirigentes não estão satisfeitos com o seu salário, especialmente se comparados com o de gestor público; 
- o nível de insatisfação salarial é substancialmente maior nos homens;

- o nível de insatisfação salarial é substancialmente maior nos directores-gerais.

\section{Conclusão}

No cenário de reformas na administração pública, cria-se novo e diferente contexto para a actuação do gestor público e para o exercício da liderança. As mais importantes iniciativas de reforma que afectaram os dirigentes públicos e, em especial, o designado Senior Public Service (OCDE, 1998) foram: 1) maior flexibilidade nos sistemas de remuneração (Austrália, Áustria, Finlândia, Irlanda, Nova Zelândia e Turquia); 2) implementação de processos de avaliação (Austrália, Áustria, Bélgica, Finlândia, EUA e Portugal em 2004); 3) termo do emprego/avaliação da performance (Canadá, Nova Zelândia, Suécia e Suíça); 4) novo sistema de selecção e novas competências (Austrália, Finlândia, EUA e Portugal em 2004); 5) nova gestão e desenvolvimento de programas de formação (Áustria, França e Nova Zelândia); e 6) implementação de novo sistema de serviço público (Holanda e Reino Unido).

Para Rodríguez-Arana (2002), a política de definição de nova filosofia de direç̧ão das pessoas dependerá da introdução de três estratégias, a saber: 1) melhorar a formação de empregados públicos; 2) promover o desenvolvimento profissional e pessoal desses trabalhadores; e 3) estabelecer uma função directiva. Os problemas dos sistemas tradicionais do funcionalismo público ou do serviço civil carecem, em geral, de capacidade para produzir perfis dirigentes na proporção requerida para as reformas (LONGO, 2002). Como refere Dror (1997), citado por
Rodríguez-Arana (2002), propõe-se, para o futuro, um modelo normativo de requisitos para um óptimo desenvolvimento de uma elite profissional na administração pública, entendida como um retracto colectivo do funcionário e uma das principais dimensões de governação, que incluem: 1) compromisso com o serviço público; 2) profissionalismo; 3) um código ético que vá além da prevenção da corrupção e redução de conflitos; 4) uma elite aberta, mas nunca uma casta; e 5) uma alta função pública que necessita de ter ou desenvolver alto conhecimento genérico sobre a dinâmica das instituições, mesmo em nível europeu.

Pacheco (2002) refere que o problema a ser enfrentado não é tanto o das interferências políticas na escolha dos dirigentes, como transparece na literatura e na visão de senso comum, mas, sobretudo, a consideração da gestão como verdadeira política pública - o que resultará em uma política mais clara e sistemática de critérios para escolha dos dirigentes. Para Gorrochategui (1999), a resposta para esse tipo de desajustamento pode ser de distinta natureza: 1) desequilíbrios do desenho institucional (do sistema de controlo, tanto no nível executivo, legislativo e judicial, como no interior do Poder Executivo); 2) as tecnologias vinculadas ao sistema de informação interna das organizações para a tomada de decisão não estão suficientemente desenvolvidas; e 3) não se ter em conta metodologias de elaboração de políticas públicas que privilegiem a transparência do processo público. $\mathrm{O}$ autor refere mesmo que algumas das características que potenciam outras condições que facilitam a discricionaridade são: 1) debilidade de oposição política para exercer um verdadeiro controlo sobre a acção do governo; 2) falta de vontade manifestada pelos 
partidos governamentais e de oposição para desenvolver acordos mínimos com respeito à forma de gestionar o exercício do poder; e 3) debilidade do sistema democrático, que não logra fazer executar o princípio de publicidade dos actos do governo.

Não se defende um modelo único para o exercício de direcção pública. Sem prejuízo do exposto, defende-se que goze de ampla aceitação o modelo proposto pela Kennedy School of Government da Universidade de Harvard, citado, entre outros, por Mark Moore (1995), em Longo (2002), que considera o directivo como criador de valor. Para o autor americano essa criação de valor implica a actuação em três esferas inter-relacionadas: 1) gestão estratégica: supõe que o dirigente reflicta estrategicamente, produza ideias acerca de como a organização pode criar valor, reformule a missão, inove quando as circunstâncias o exijam; 2) political management: ou, como lhe chama Longo (2002), gestão da mudança política, no sentido de obter legitimidade e apoio de diversos actores, entre os quais se incluem os superiores políticos; e 3) gestão operativa: deve conseguir-se que a organização actue eficaz e eficientemente para alcançar os objectivos da missão e assuma a responsabilidade dos resultados alcançados. No modelo proposto por Moore (1995), o dirigente público terá três esferas de competências: 1) a gestão estratégica; 2) a gestão operacional; e 3) a gestão das relações políticas. Esta última diz respeito à gestão da inter-relação com os stakeholders (actores que não estão sob a autoridade do dirigente, mas são fundamentais para $\mathrm{o}$ alcance dos seus resultados). $\mathrm{O}$ importante a destacar é que, segundo essa concepção de competências de direcção, o dirigente público busca maximizar o apoio desses stakeholders para garantir melhores resultados das actividades sob sua responsabilidade, e não para aumentar o seu poder pessoal (PACHECO, 2002).

Conclui-se, portanto, que tanto o modelo politizado como o modelo tradicional de função directiva têm as suas vantagens e inconvenientes, mas as vantagens do modelo profissional são superiores num regime democrático consolidado (Mendieta, 2001), apesar do que refere Morgan (1994), citado por Mendieta (2001): o modelo politizado tem como perigos o jacobinismo e o abuso das maiorias nos regimes democráticos e o abuso de poder, assim como o desrespeito pelos procedimentos e pela tomada de decisão. Mas o modelo profissional também tem os seus perigos, pode dar lugar a excessos burocráticos, a jogos de poder em que a burocracia abusa de sua permanência e do controlo da informação para poder defender as suas próprias opções de política e os interesse corporativos. Pode, ainda, ser insensível à maioria obtida nas urnas, despreocupando-se com as preferências dos eleitores, assim como gerar um forte imobilismo.

Para Denhardt (1999), as competências do futuro administrador público serão: 1) liderança e habilidades associadas a essa liderança, tal como o trabalho em equipa, capacidade de resolução de conflitos, negociação, cooperação e tomada de decisão em ambientes multiculturais; 2) competências de comunicação (oral, escrita, informática e línguas estrangeiras); 3) criatividade e raciocínio ético; 4) relações humanas capazes de produzir e realizar com sucesso e em ambiente de rápida mudança; 5) comprometimento emocional e psicológico; 6) apreciar a diversidade do comportamento e da experiência humana, incluindo as actividades criativas; 
7) comportamento comprometido com os valores do serviço público da nação e do mundo; e 8) excelente capacidade de relações interpessoais e de grupo.

Num estudo da OCDE (1998) em que se questionou uma série de países para indicarem as competências que se tornaram (com maior ou menor grau) importantes, na última década, para o Senior Public Service, as respostas indicaram que o perfil desses funcionários está a mudar na maioria dos serviços públicos, uma nítida preferência por métodos baseados em competências de gestão que propriamente em competências de especialidade. As principais competências apontadas foram: 1) liderança; 2) visão estratégica; 3) capacidade e iniciativa para a mudança; 4) habilidade e competências gerais da gestão; 5) habilidades para gerir pessoas e relações interpessoais; 6) espírito de equipa; 7) comunicação; e 8) habilidades de IT.

Para resolver o problema das frágeis (e da falta de) competências no sector público, uma variedade de iniciativas muito aproximadas foi tomada por países membros da OCDE (2000). Nesse sentido, alguns países optaram por dar mais enfoque na mudança e no profissionalismo dos trabalhadores existentes, outros fizeram a opção pela ênfase em outras formas de recrutamento de forma a criar competências na administração pública (sector do Estado). Essas opções traduziram-se em: 1) incremento de novos sistemas retributivos baseados na performance (com o sentido de reter os melhores trabalhadores, por meio de salários mais competitivos); 2) melhoramento da imagem do governo e, em especial, dos serviços públicos; 3) incremento das relações entre o público e o privado; 4) recrutamento nas universidades; e

5) ênfase nos benefícios do emprego público (trabalho flexível, facilidades em sistemas de saúde alternativos, desenvolvimento de carreira, etc.).

A liderança é um dos principais aspectos de uma boa governação pública (OCDE, 2001). O papel mais importante dos líderes do sector público consiste, assim, em resolver os problemas e as dificuldades que se colocam no ambiente público. A liderança é uma variável de primeira importância, que conduz a uma melhoria da capacidade da gerência e do desempenho da organização. As tendências gerais do desenvolvimento da liderança em alguns países da OCDE são, segundo o estudo em referência: 1) desenvolvimento de estratégias conjuntas (por exemplo, no Reino Unido, começou-se recentemente a elaborar um modelo de formação para os dirigentes, como é o caso de Portugal); 2) criação de organismos responsáveis pela formação dos dirigentes (como nos EUA e na Suécia e do exemplo do INA em Portugal); 3) inclusão, nos programas de formação em gestão para os dirigentes, do componente liderança (Irlanda). Apesar da diversidade de estratégias e de aproximações nos países membros, fica claro que as experiências dos diferentes países possuem tendências comuns a propósito da formação dos futuros dirigentes, a saber: a definição do perfil de competências, a identificação e a selecção dos futuros dirigentes, o encorajamento da formação e, em especial, a formação contínua e, por último, desenvolvimento durável da liderança.

O exercício de fortes lideranças no sector público implicará, como revela estudo de Draper (2002), a propósito das necessárias mudanças para a administração pública para os próximos anos, entre outras observações (melhores serviços 
públicos para o cidadão, melhor coordenação horizontal de serviços, etc.), a necessidade de desenvolver competências em nível de liderança, visão e planejamento estratégico. Nesse contexto, julgase que, em Portugal, se fizeram mais progressos nos últimos meses (com o papel preponderante do INA e da Secretaria de Estado da Administração Pública) que nas últimas duas décadas juntas, em nível de reforma da formação do pessoal dirigente.

(Artigo recebido em junho de 2006. Versão final em julho de 2006)

\section{Notas}

${ }^{1}$ Em Portugal, a Lei no 2, de 15 de janeiro de 2004, alterada pela Lei no 51, de 30 de agosto de 2005, aprova o estatuto do pessoal dirigente dos serviços e organismos da administração central, regional e local do Estado.

${ }^{2} \mathrm{O}$ Top Public Service (TPS) não se confunde com Top Management Service (TMS) já que aquele (TPS) se refere a posições políticas, pelo menos, de livre escolha e de designação política, não excluindo que, para alguns países, as duas situações (política e não política) se encontram por vezes nesse grupo de designações, enquanto este (TMS) é um reconhecido (normalmente) e estruturado sistema de gestão de pessoal para as posições do alto funcionalismo público, mas não são políticas ou, pelo menos, de escolha ou designação do poder político (OCDE, 1995). A título de exemplo, no caso português o Top Public Service é o equivalente aos nossos directores-gerais, secretários-gerais, inspectores-gerais e directores municipais $\left(1^{\circ} \mathrm{e} 2^{\circ}\right.$ grau dos cargos de direcção superior); o Top Management Service é o equivalente aos nossos directores de departamento e chefes de divisão e equiparados $\left(1^{\circ} \mathrm{e} 2^{\circ}\right.$ grau dos cargos intermédios). Ambos os subsistemas pertencem ao grupo do Senior Public Service. A expressão Political Civil Servants dada às posições do TPS não deve ser confundida com as do TPM. Aquelas, ao contrário destas, são posições administrativas (TMS) e não posições políticas (TPS). O mesmo é dizer, socorrendo-nos do caso português, que os directores-gerais e inspectores-gerais (entre outros) fazem parte do Political Civil Servants e que os directores de serviço e chefes de divisão assumem-se (pelo menos desde 1997) como posições administrativas, não políticas, embora não incluídas em carreira, fazendo, da mesma forma, parte dos designados "cargos híbridos". A palavra executive, muito usada na América do Norte e no Pacífico para designar Top Managers é enganadora: no Reino Unido e na Irlanda é aplicada aos níveis mais baixos do funcionalismo público cujos ocupantes são recrutados sem qualquer formação universitária (OCDE, 1995). O adjectivo sénior pode ser confundido, em alguma aparência, com seniority (antiguidade). A expressão bigher civil service é muito usada para substituir a expressão cadres supérieurs e/ ou baut fonctionnaire (França); e o Senior Executive Service tem o mesmo significado que a expressão Senior Civil Service (por exemplo nos EUA e no Reino Unido).

${ }^{3}$ Os brevíssimos comentários e/ou conclusões (proposições) que se apresentam resultam de estudo empírico desenvolvido por nós, tendo abrangido todos os dirigentes não equiparados, num total de 226 dirigentes, assim discriminados: 44 directores-gerais; 13 secretários-gerais; 16 inspectoresgerais; 100 subdirectores-gerais; 24 secretários-gerais-adjuntos; 29 subinspectores-gerais. Do total da população de interesse, houve uma receptividade de 81 dirigentes, o que equivale a $35,8 \%$ do total (Nunes, Pedro. O perfil dos dirigentes no actual contexto da nova gestão pública em Portugal: especial referência aos cargos de escolha política. 2003. Tese (Doutoramento em Gestão) Escola de Gestão do ISCTE, Lisboa). 


\section{Referências bibliográficas}

Aberbach, Joel D.; Putnam, Robert D.; Rockman, Bert A. Bureaucrats and politiciansin western democracies. Cambridge Massachusetts: Harvard University Press, 1981.

Abramson, Mark A.; Clyburn, Steven A. Results of the government leadership survey: a 1999 survey of federal executives, Arlington, USA: PricewaterhouseCoopers, Research Center, 1999.

BeKke, Hans A. G. M.; MeER, Frits M. van der. Civil service systems in Western Europe: civil service systems in comparative perspective. Cheltenham (UK): Edward Elgar, 2001.

Bourgault, Jacques et al. Les rôles et les compétences des gestionnaires supérieurs du gouvernement du Québec pour l'avenir. Québec, Canadá: UQAM/ENAP, 2003.

Brans, Marleen.; Hoet, Dieter; Pelgrims, Christophe Politico-administrative relations under coalition governments: the case of Belgium. Public Management Institute, Department of Politics, Belgium, 2002.

Braun, Gérard. Etude comparative portant sur la réforme de l'Etat à l'étranger. Rapport d'information n.348 (2000-2001), Commission des Finances, 31 mai 2001.

Brezis, Elise. S.; Crouzet, François. Changes in the recruitment an education of upper elites in twentieth century western countries. In: Economic History CONGRESs, XIII, Buenos-Aires, Argentina, 2002.

CHAnda, Ateesh. Systems of political appointment. Hong Kong : Civic-Exchange Publications, 2001.

Curado, Maurício Fleury. The Senior Executive Service in the United States of America: struggle for consolidation. The George Washington University, Institute of Brazilian Business and Public Management Issues (IBI), The Minerva Program, 1999.

Denhardt, Robert B. The future of public administration. Public Administration \& Management, 4, p. 279-292, 1999.

DrAPER, Gordon. Strengthening public service leadership development: perspectives from the developing world. In: United Nations Expert Group MeEting on New Challenges for Senior Leadership Enhancement for Improved Public Management in a Globalizing World. Turin, Italy, 19-20 September 2002.

Eymeri, Jean-Michel. Pouvoir politique et haute administration: une comparaison européenne. Maastricht, the Netherlands/Pays-Bas: European Institute of Public Administration,.2001.

GaEtani, Francisco. Com quem contar para dirigir as acções do governo? Com quem governar? In: Seminário Internacional: Capital Humano e Governança: Balanço e Desafios da Administração Pública. Brasília, DF, 4 e 5 jun. 2002.

Giordan, Sonia Elizabeth Oria. Los gerentes públicos en la gestión del cambio. In: Congreso Internacional del CLAD sobre la Reforma del Estado y de la Administración Pública, 7, Lisboa, 2002.

Gorrochategui, Nora. Medidas preventivas de la corrupción en el funcionamiento del aparato público. Revista del CLAD, Reforma y Democracia, IV Congreso Internacional del CLAD, sobre reforma del Estado e administración pública, México, Out, 21, Caracas, p. 19-22. (1999). 
HANSEn, Kasper M.; EJERSBo, Niels. The relationship between politicians and administrators - a logic of disharmony. Public Administration, v. 80, n. 4, p. 733-750, 2002.

HARB, Antonio Geraldo. A determinação das competências essenciais, segundo a percepscão de gestores, funcionários e clientes, na busca da competitividade do setor supermercadista na cidade de Manaus. Banco de teses da Universidade Federal de Santa Catarina, Brasil, 2001.

Instituto de Gestão de Base de Dados dos Recursos Humanos da Administração PúBLICA $A$ administração pública em números, $1^{\circ}$ recenseamento geral da administração pública. v I, Lisboa, 1999.

JACOBSEn, Ingvar Dag. Are the relations between politicians and administrators at the local level determined by the degree of central government regulations? In: ECPR, JINT SEssions Workshops, 21, Grenoble, abr. 2001.

Korsmit, J. C.; Velders, B. Action plan for the development of Senior Public Service in the Netherlands - civil service in comparative perspective. Indiana: Indiana University School of Public and Environmental Affairs: 1997 (Conference).

Lacoviello, M. El juego político y las estrategias de recursos humanos en las organizaciones públicas. Argentina, Cuaderno CEPAS n. 4, Centro de Estudios de Política, Administración y Sociedad, 1996.

LAForte, Denis; Godin, Richard. Vers un nouveau profil de cadre en. management public (Australie, Canada, France, Royaume-Uni). Télescope, Canada, v. 8, n. 3, juin 2001. LONGO, Francisco. Reforma del empleo público: tótem y tabú. Barcelona: Diputación de Barcelona, España, 1997.

. El desarrollo de competencias directivas en los sistemas públicos: una prioridad del fortalecimiento institucional. CONGRESO INTERNACIONAL DEL CLAD SOBRE la Reforma del Estado y de la Administración Pública, 7, Lisboa, 2002.

Loureiro, Maria Rita; Abrucio, Fernando Luiz; Rosa, Carlos Alberto. Radiografia da alta burocracia federal brasileira: o caso do Ministério da Fazenda. Revista do Serviço Público, Ano 49, n 4, 1998.

Machado, Eduarda C. M. C. A relação entre políticos e burocratas. Escola de Economia e Gestão. Braga (Portugal), Universidade do Minho: 234, 1999.

Mendieta, Manuel Villoria.. La capacitación de los directivos públicos en las administraciones españolas y latinoamericanas. Revista del CLAD, Reforma y Democracia, Caracas, out, 21, 2001.

Nunes, Pedro. O perfil dos dirigentes no actual contexto da Nova Gestão Pública em Portugal: especial referência aos cargos de cscolha política. 2003. Tese (Doutoramento em Gestão). Escola de Gestão do ISCTE, Lisboa.

OCDE. Top management service in central government. introducing a system for higher civil service in central and eastern European countries. Paris, a Joint initiative of OCDE/ CCET and EC/PHARE, SIGMA: Support for Improvement in Governance and Management in Central and Eastern European Countries, 1995.

PUMA, 1996.

. Gestion du capital bumain et réforme de la fonction publique. Paris: OCDE; 
. Measuring public employment in OECD countries: sources, methods and results.

Paris: OCDE; PUMA, 1997.

Managing the senior public service: a survey of OECD countries. Paris:

Organisation for Economic Co-Operation and Development, 1998.

Principles for managing ethics in public sector. OCDE Policy Brief, Public Management Service, Paris, n. 4, 1998.

. Building public trust. ethics measures in OECD countries. OCDE, Public Management Policy Brief, Paris, n. 7, 2000.

. Developpements récents de la gestion des ressources humaines dans les pays membres de L'OCDE. Paris : OCDE ; PUMA/HRM, 5/FINAL, 2001.

. Public service as an employer of choice. Paris: OCDE Observer, Policy Brief, 2002.

OszLak, Oscar. El servicio civil en America Latina y el Caribe: situacion y retos futuros. Documento de Trabajo. Banco Interamericano de Desarrollo, Washington, D.C., abr. 26 y 27, 2001.

PACHECO, Regina Silvia. Mudanças no perfil dos dirigentes públicos no Brasil e desenvolvimento de competências de direcção. In: Congresso Internacional del CLAD sobre la Reforma del Estado y de la Administración Pública, 7, Lisboa, 2002.

Page, Edward C.; Wright, Vincent. Bureaucratic elites in western European States: a comparative analisys of top officials. Oxford University Press, 1999.

Parrado-Díez, Salvador. Controlling the acess to the Spanish summit (1938-1993). Paper presented at the Groupe de Travail, Histoire de L'Administration, International Institute of Administrative Sciences, ref. Doc. 66, 24-25 Mar.1996.

. The development and current features of the Spanish civil service system.

Civil service systems in western Europe. E. Elgar. Northampton, USA, p. 247-274, 2001.

Petermann, S. La réforme de systèmes politico-administratifs: le cas américan pour éclairer le cas belge? Liege: Universite de Liege, Faculte de Droit, Section de Sciences Politiques, 2001.

Peters, B. Guy. Politicians and bureaucrats in the politics of policy-making. London: SAGE, 1987.

Peters, B. Guy; Pierre, Jon Politicization of the civil service: concepts, causes, consequences. Gothenburg: 1999. (Conference on Politicisation of the Civil Service)

PoLLITT, Christopher. Managerialism and the public services: the Anglo-American experience. Oxford/Massachusetts: Blackwell, 1990.

POLLiTT, Christopher; BouCKAERT, Geert. Public management reform: a comparative analysis. Oxford: Oxford University Press, 2000.

PopIK, Sebastián. Una agenda de investigacion sobre la reforma de la administracion publica en la Argentina. Centro de Estudios para el Desarrollo Institucional, documento n. 13, jul.1998.

Rodríguez-Arana, Jaime; Herrán, Gloria Martínez. La formación de directivos en la administración pública española. In: CONGRESSO INTERNACIONAL DEL CLAD SOBRE LA Reforma del Estado y de la Administración Pública, 7, Lisboa, 2002. 
SARAVIA, Enrique. La situación laboral del personal de la administración pública. Serie documentos e reuniones internacionales. Revista del CLAD, Reforma y Democracia, Santo Domingo, n. 1, 1997.

Schnapp, Kai-Uwe. Derived veto position of ministerial bureaucracies: a comparative description. In: SOG Tokyo Conference, The Quest for Governance: Reforms, Renovation, and Retrenchments in Governance. Tokyo, Nov. 1999. p.17-19.

SEvic, Zeljko. Politico-administrative relations in small States. Bank of Valletta Review, n. 23, UK, Spring. 2001.

Shergold, Peter. Wielding the bureaucracy for results: an Australian perspective. Asian Review of Public Administration, IX, n. 2, 1997.

SILGUY, Yves-Thibault de. Moderniser l'Etat: le cas de l'ENA. Comission sur la réforme de 1 'ENA et la formation de cadres supérieurs des fonction publiques, França, 2003.

Sotiropoulos, Dimitri A.; Bourikos, Dimitris. Ministerial elites in Greece, 1843-2001: a synthesis of old sources and new data. Athens: Center for European Studies; University of Athens, 2001. (Working Paper, 9)

SVARA, James H. Dichotomy and duality: reconceptualizing the relationship between policy and administration in council-manager cities. Public Administration Review, 45, p. 221-232, 1999.

Waintrop, Françoise et al. Réforme l'encadrement supérieur. l'expérience de sept pays. Rapport d'étape, Institut de la Gestion Publique et de la Développement Économique. France, fév. 2003. 
Resumo - Resumen - Abstract

\section{O Senior Executive Service: especial referência ao perfil do Top Public Service em Portugal \\ Pedro Nunes}

No contexto de reforma da administração pública, o objectivo do trabalho pretende dar conta das características dos modelos de direcção pública, em particular dos dirigentes (Senior Executive Service: Top Public Service e Top Management Service), e do seu perfil em face dos novos desafios da administração pública. O objectivo principal deste trabalho foi caracterizar o sistema de designação/ nomeação para os cargos de dirigente de livre escolha política, sistema conhecido na literatura como spoil system, com especial referência ao $1^{\circ}$ e $2^{\circ}$ níveis, grupo I, dessas funções, no contexto da elite das direcções-gerais em Portugal.

Palavras-chave: reforma administrativa; directivos públicos; recrutamento e selecção

\section{E1 Senior Executive Service: especial referencia al perfil del Top Public Service en Portugal \\ Pedro Nunes}

En el contexto de reforma de la administración pública, este artículo intenta dar cuenta de las características de los modelos de dirección pública, en particular de los directivos (Senior Executive Service: Top Public Service e Top Management Service) y de su perfil frente a los nuevos retos de la administración pública. El objetivo principal de este trabajo fue caracterizar el sistema de designación/ nombramiento para los cargos de directivo de libre elección política, sistema conocido en la literatura como spoil system, con especial referencia al $1^{\circ}$ y $2^{\circ}$ nivel, grupo I, de esas funciones, en el contexto de la elite de las direcciones-generales en Portugal.

Palabras claves: reforma administrativa, directivos públicos, reclutamiento y selección

The Senior Executive Service: special reference to the profile of the Top Public Service in Portugal

Pedro Nunes

Within the context of the public administration reform, this article intends to address some of the characteristics of the public management models, particularly concerning the Senior Managers (Senior Executive Service: Top Public Service and Tpo Management Service) and their profile regarding the new challenges of the public administration. The main objective of this paper was to describe the political appointment system to leading positions in the public service (Senior Executive Service), known in the literature as "spoil system", with special reference to the 1st and 2nd levels, group I, positions held by the elite of the ministerial cabinets in Portugal.

Key words: administrative reform; senior executive service; recruitment and selection

Pedro Nunes

Professor-coordenador e presidente do Conselho Científico da Escola Superior de Gestão do Instituto Politécnico do Cávado e do Ave (Portugal), doutor em Gestão e director da revista Polytechnical Studies Review. Contato: <pnunes@ipca.pt> 